\title{
The Model Establishment of Force to Crank Angle under Idling in Vehicle
}

\author{
XU Run", LIU Jiaguang
}

Mechanical Electric Department, Wen Jing College, Yamtai University, Yantai 264005, China

DOI: $10.36348 /$ sjet.2021.v06i04.003

| Received: 10.03.2021 | Accepted: 17.04.2021 | Published: 22.04.2021

*Corresponding author: XU Run

\section{Abstract}

With inclining the speed of vehicle the cost will become low dominantly when the speed attains $750 \mathrm{Km} / \mathrm{h}$ and $\mathrm{crank}$ length is $70 \mathrm{~mm}$. With increasing time the speed and force of vehicle will become periodic wave. When the crank length increases from $70 \mathrm{~mm}$ to $100 \mathrm{~mm}$ under $750 \mathrm{r} / \mathrm{m} 850 \mathrm{r} / \mathrm{m}$ and $950 \mathrm{r} / \mathrm{m}$, the speed will increase and and the force will decrease. The force will decline with inclining rotation and crank force respectively. So it is chosen of the short crank and idling so as to maintain maximum force. The effect of crank length and rotation to force is about $20 \mathrm{~m} / \mathrm{s}$ and $70 \mathrm{KN}$ in this study. At the force with $750 \mathrm{r} / \mathrm{m}$ and crank length with $100 \mathrm{~mm} \& 70 \mathrm{KW}$ it will be the lowest which is benefit for engine wear.

Keywords: Modeling; kinematics; crank length; speed: force; angle; idling; vehicle.

Copyright (C) 2021 The Author(s): This is an open-access article distributed under the terms of the Creative Commons Attribution 4.0 International License (CC BY-NC 4.0) which permits unrestricted use, distribution, and reproduction in any medium for non-commercial use provided the original author and source are credited.

\section{INTRODUCTION}

The idling is important factor in vehicle since its function is significant in vehicle driving. It can be used in any status for parking and driving the vehicle temporarily. Its wear can be increased if it is unstable. Moreover the sulphur in oil can create sulphide at high temperature which makes the finish degree to lose on the cylinder wall through pasting it. So it is searched that the idling condition has been studied in this paper to find the intrinsic relationship between them. The speed and force is to be found the necessary parameters in crank mechanism movement in kinematics of vehicle. So in a cycle the investigation into kinematic movement is important. Firstly through speed of vehicle exhibits the force size directly. It is observed through curve tendency. Secondly the force expresses the force through detail tendency. It is expressed that define value of force change. In order to save material and cost the data on them is essential at all. Such as the detail material choice and manufacture cost is needed reasonably and economically. In this paper the speed and force is computed through model and it is valuable on their data and tendency. Further research is needed to these parameters behavior to grasp these rule and data. Because the vehicle is applied to many factories the crank is a important mechanism in punch component [1-4]. So the speed of work is most important one to control the production. We shall compute and model the parameter to find a economic mechanism to its application to product designer, operating engineer and machine maker.

The dynamics can be used in crank and crank parts, because its piston can work through the them. On the low speed of $30 \mathrm{Km} / \mathrm{h}$ which is the vehicle cycle speed in general the vehicle is to be compared with it for preventing from traffic accident if it is beyond the vehicle cycle. In the process of designing, the piston press is connected into their procedures, and in a short time to complete the continuous processing of the piston circulation [5-7]. They produce a lot of products in a certain amount of time. Since the they are an automatic movement vehicle, it is difficult to control the control. So we should focus on this control issue and work for scientific management, networking and digital design and management. Due to excessive piston and crank mechanism fatigue and the piston processing speed is also fast, we need to carry out timely routine inspection of the engine and focus on the hidden faults. This saves the cost of the inspection to the manufacturer's personnel for repair due to machine failure and the loss caused by the fault of the machine. Because the load and frequency of the mechanism does not keep up with the loss caused by the fatigue condition under the load of the vehicle and the engine in special, the economic efficiency of the control structure of the crankshaft with related parts is an important 
factor in the vehicle. This paper discusses the crankshaft from the technical view of economic benefit. The crank is the most critical transmission power mechanism, which turns the rotating motion of the crank and crank into the rotation of the engine and pushes and presses the piston surface. Therefore, the kinematics and dynamics of the crank are studied in order to optimize the crank parameters and high efficiency.

\section{Kinematic equations}

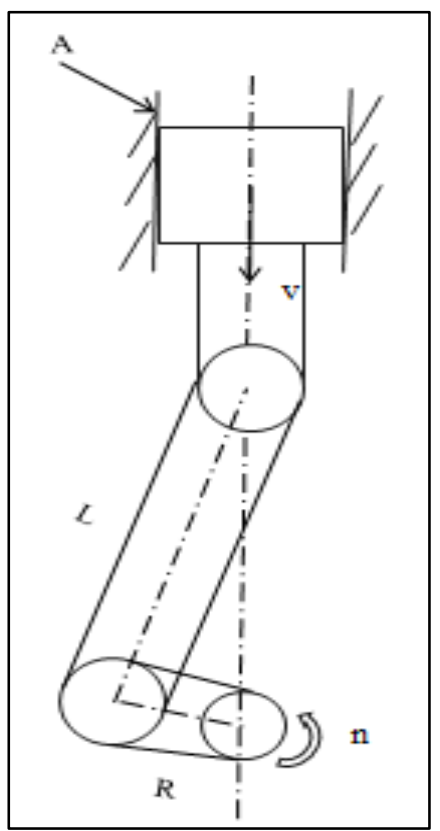

Fig-1: The kinematic of crankshaft crank length in the engine of vehicle

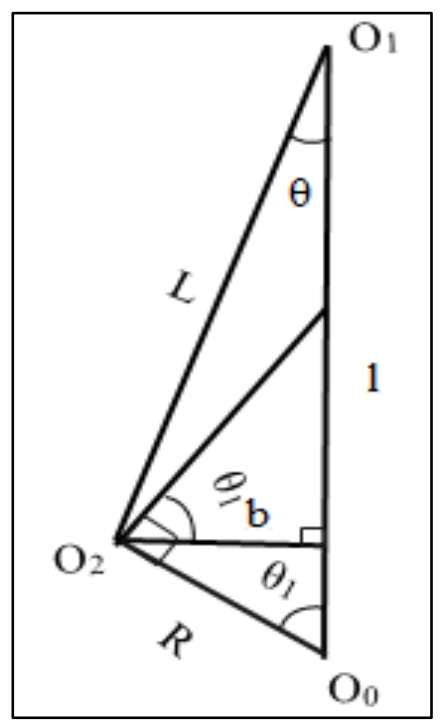

Fig-2: The kinematic of crankshaft crank mechanism in engine of vehicle

From Figure 2 it has

$$
L / \sin \theta_{1}=R / \sin \theta
$$

It is formula for $\theta$ of vehicle and crank.

$$
\begin{aligned}
& \text { Here } \theta_{1}=2 \pi n t / 60 \\
& \text { Since } \Delta l=L\left(\cos \theta_{1}-1\right)+R \cos \theta+R \\
& \text { It has } \\
& v=\frac{2 \pi R n}{60 \sin \theta_{1}} \\
& F_{1}=9.55 \frac{P}{n R \sin \theta_{1}}
\end{aligned}
$$

Here as seen in Figure 1 and $2 \mathrm{n}$ is rotation in shaft, $\mathrm{r} / \mathrm{min}$; $\mathrm{L}$ is the crank length, $\mathrm{m}$; $\mathrm{R}$ is crank length, $\mathrm{m} ; \theta$ is angle of crank and center line, ${ }^{\circ} ; \theta_{1}$ is angle of crank and center line, ${ }^{\circ} ; \Delta \mathrm{L}$ is the piston relative movement; crank end piston speed $\mathrm{v}, \mathrm{m} / \mathrm{s}$; piston force $\mathrm{F}_{1}$, KN.

\section{DISCUSSIONS}

It is investigated that what the speed changes when crank length $R$ inclines from $70 \mathrm{~mm}$ to $100 \mathrm{~mm}$ in vehicle of machine meanwhile what the speed changes when the rotation becomes from $750 \mathrm{r} / \mathrm{m}$ to $950 \mathrm{r} / \mathrm{m}$ during one cycle course time is detailed explanation in this study. The size of crank length is chosen reasonably for optimum vehicle crank length. It is investigated which $\mathrm{R}=70 \mathrm{~mm}, 85 \mathrm{~mm}$ and $100 \mathrm{~mm}$ under $\mathrm{L}=140 \mathrm{~mm}$, $160 \mathrm{~mm}$ and $180 \mathrm{~mm}$ is the best one since its energy saving is attained not only, but also the fit vehicle work size with $14 \mathrm{~cm}, 17 \mathrm{~cm}$ and $0 \mathrm{~cm}$ which is the lowest to compare with others in this study. The longest size is for $\mathrm{R}=100 \mathrm{~mm}$ and $\mathrm{L}=180 \mathrm{~mm}$ which has the $0 \mathrm{~cm}$ one for the deepest vehicle. When the $\Delta \mathrm{l}$ is functional it is considered that it is differential $\mathrm{dl}$, then it is used that differential $\mathrm{dl} / \mathrm{dt}$ is to be integrated the whole cycle to solve speed, meanwhile the $\mathrm{dv} / \mathrm{dt}$ is to be done to solve the force.

It shows the maximum force with different crank length $\mathrm{L}=180 \mathrm{~mm}$. The periodic distribution of maximum three parameters is from $0.08 \mathrm{~s} \& 0.07 \mathrm{~s}$ to $0.063 \mathrm{~s}$ for rotation with $750 \mathrm{r} / \mathrm{m}, 850 \mathrm{r} / \mathrm{m}$ and $950 \mathrm{r} / \mathrm{m}$. The high efficiency is high one with long crank length and high rotation which causes high force and rapid work to apply to. Deep working with high force and deep movement is adopted big crank length. It may be deduced from the formula which can incline the force with long crank so the force will be inclined correspondingly.

Figure 3 shows that speed of vehicle becomes periodic wave when the time changes. Meanwhile the one does when the crank and crank length changes. It will be periodic from zero to positive position then from positive to zero then to negative one finally becomes zero with a circle. When crank length is $100 \mathrm{~mm}$ and crank length is $180 \mathrm{~mm}$ the highest movement is formed, then crank length is $85 \mathrm{~mm}$ and crank length is $160 \mathrm{~mm}$ and the lowest movement is crank length is 
XU Run \& LIU Jiaguang; Saudi J Eng Technol, Apr, 2021; 6(4): 62-66

$70 \mathrm{~mm}$ and crank one is $140 \mathrm{~mm}$. Here the role of crank length is a little and main is crank length. It shows that with increasing crank length $\mathrm{R}$ from $70 \mathrm{~mm}$ to $85 \mathrm{~mm}$ the valley speed becomes small. Overviews with increasing crank angle it becomes periodic wave and with increasing crank length it will incline from $-00 \mathrm{~m} / \mathrm{s}$ to $-280 \mathrm{~m} / \mathrm{s}$ when the angle is $180^{\circ}$. The speed becomes periodic wave when the angle attains periodic $360^{\circ}$ and it shows that speed effect of crank length turn is in relation to the increasing angle in this study. In general the difference between them is about size with $0 \mathrm{~m} / \mathrm{s}$. Figure 3 shows that the speed with the detail $\theta_{1}$ at $\mathrm{R}=70 \mathrm{~mm}$. The one with $950 \mathrm{r} / \mathrm{m}$ is large them $850 \mathrm{r} / \mathrm{m}$ and at last $750 \mathrm{r} / \mathrm{m}$. that's saying that more big speed is gained with inclining rotation. The same as the crank length happens as well.

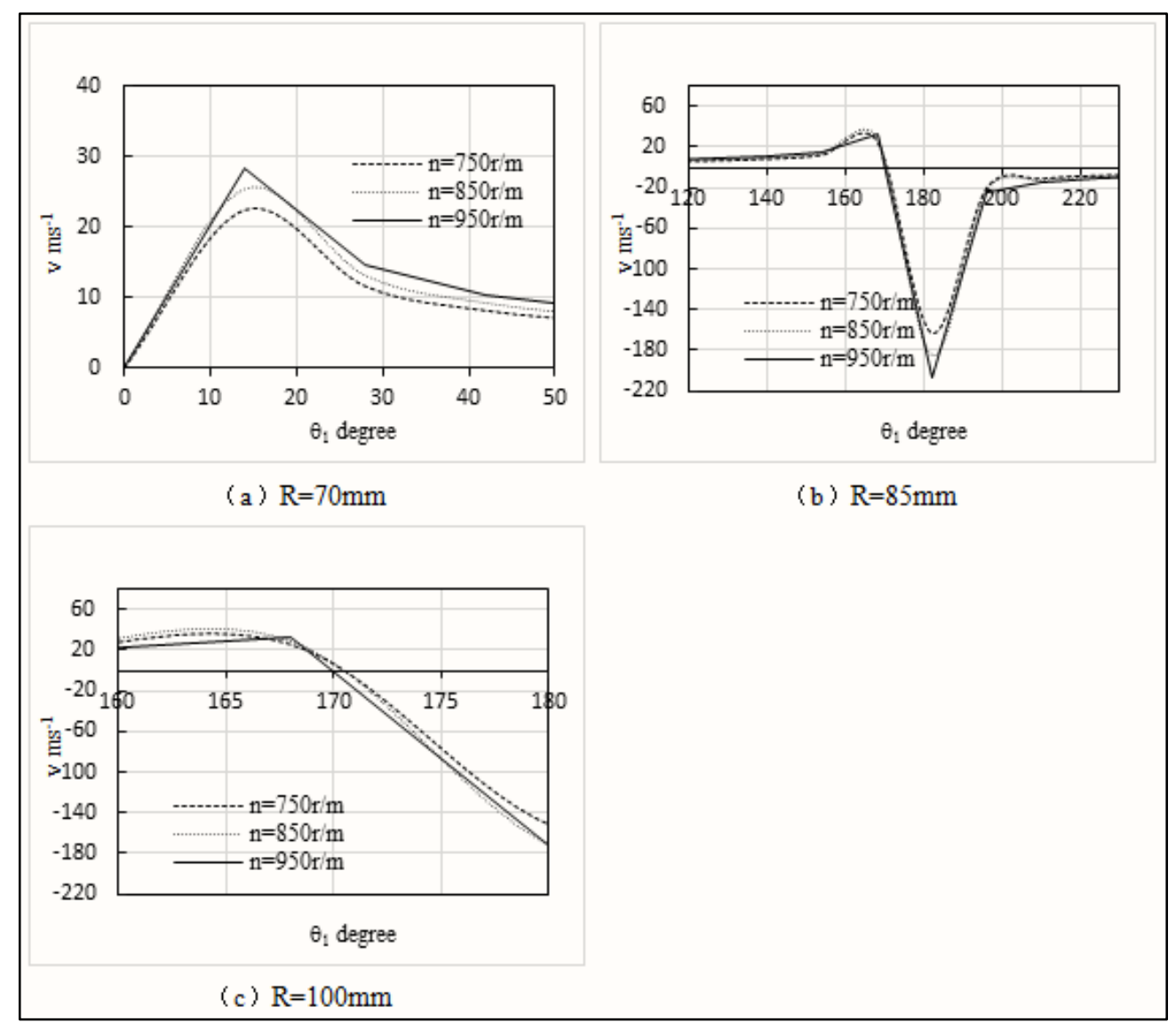

Fig-3: Relations of piston speed and angle $\theta 1$ with the parameter $R=70 \mathrm{~mm}$ and rotation

In Figure 4 shows the curve of force with two parameters. The condition in this paper is $R=70 \mathrm{~mm}$, $85 \mathrm{~mm}$ and $100 \mathrm{~mm}$ and $\mathrm{L}=140 \mathrm{~mm}, 160 \mathrm{~mm}$ and $180 \mathrm{~mm}$. The similar status will be found too to compare with Figure 3. It is here not to be mentioned again. The mentioned point is with increasing from $\mathrm{R}=70 \mathrm{~mm} \&$ $\mathrm{L}=850 \mathrm{~mm}$ to $\mathrm{L}=100 \mathrm{~m} / \mathrm{m}$ the force will become low. That means that the high power will be formed at low crank length. The rotation of $750 \mathrm{r} / \mathrm{m}$ is needed in heavy load such as the load goods and person even slope road in driving operation. If the rotation is big the speed of vehicle becomes small. So increasing rotation is to incline vehicle force from $850 \mathrm{r} / \mathrm{m}$ to $950 \mathrm{r} / \mathrm{m}$, it is not one way to regulate. Another is that regulation of decreasing crank length is to increase the force in a vehicle. Both of them are important to control the vehicle speed and force in designing vehicle. In this study the rotation is not concerned as a including power kinematic model so linkage length is neglected.

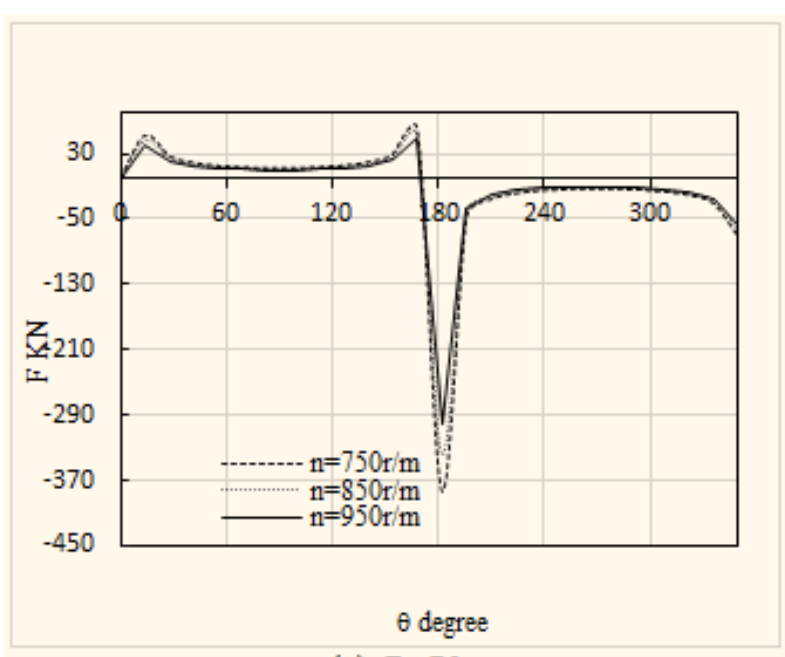

(a) $\mathrm{R}=70 \mathrm{~mm}$ 
XU Run \& LIU Jiaguang; Saudi J Eng Technol, Apr, 2021; 6(4): 62-66

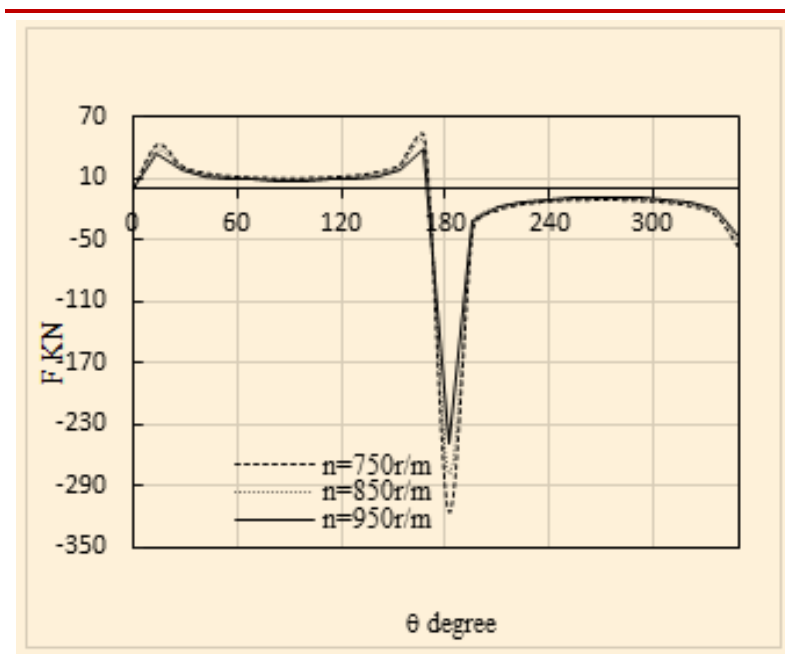

(b) $\mathrm{R}=85 \mathrm{~mm}$

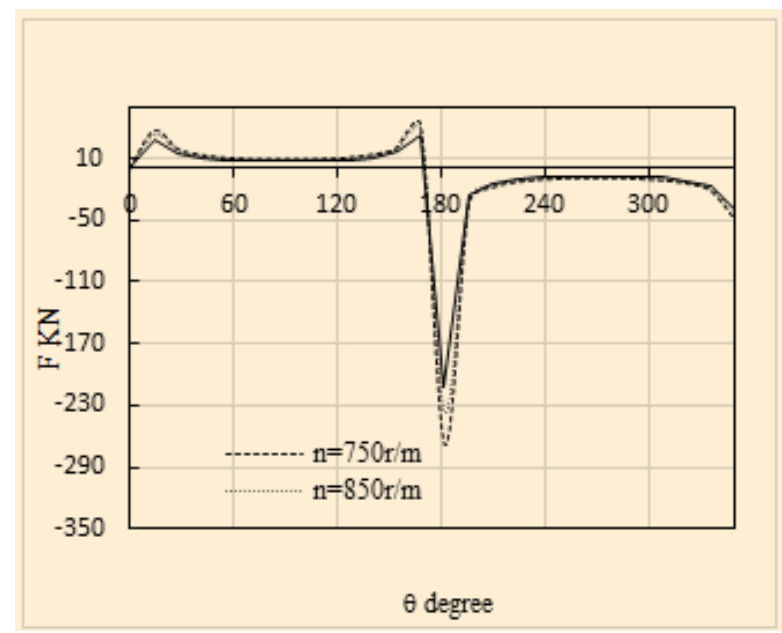

(c) $\mathrm{R}=100 \mathrm{~mm}$

Fig-4: Relations of piston force and angle $\theta_{1}$ with the parameter $R$ and rotation at $70 \mathrm{KW}$ of vehicle engine

Figure $5(\mathrm{a} \sim \mathrm{c})$ shows that the force forms periodic when the angle increases and then it forms periodic wave under $n=750 \mathrm{r} / \mathrm{m}, 850 \mathrm{r} / \mathrm{m}$ and $\mathrm{n}=950 \mathrm{r} / \mathrm{m}$ at $70 \mathrm{KW}$ engine power. The summit was large when the angle is $180^{\circ}$, and then forms another summit with periodic wave when the angle is $0^{\circ}$. Figure $5(\mathrm{~b})$ curves summit change to be larger at $\mathrm{n}=850 \mathrm{r} / \mathrm{m}$ while the phase angle becomes $0^{\circ}$. It indicates that the force summit increases with increasing rotation, and repeats with phase angle. It explains the movement is zero with center line so the biggest force happens as seen in Figure 5(c). However the opposition movement force forms second summit which is smaller than the first one. With decreasing crank length the force will incline. In general the power will become strong when short crank length is. In the place where it need small force the long crank length is available for design. It is not considered the power is unchangeable in transmission of dynamics so the force at $950 \mathrm{r} / \mathrm{m}$ is bigger than at $750 \mathrm{r} / \mathrm{m}$. The small length of crank is also somewhat bigger than the long one. The effect of crank length is considered not to be small that is the formula does not include $\mathrm{L}$ and however includes $\mathrm{R}$ so the linkage length is neglected in this study.

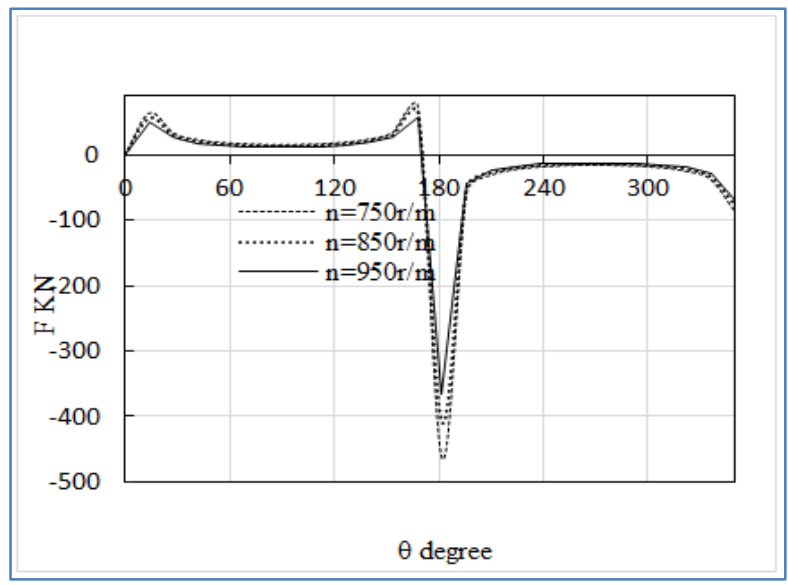

(a) $\mathrm{R}=70 \mathrm{~mm}$

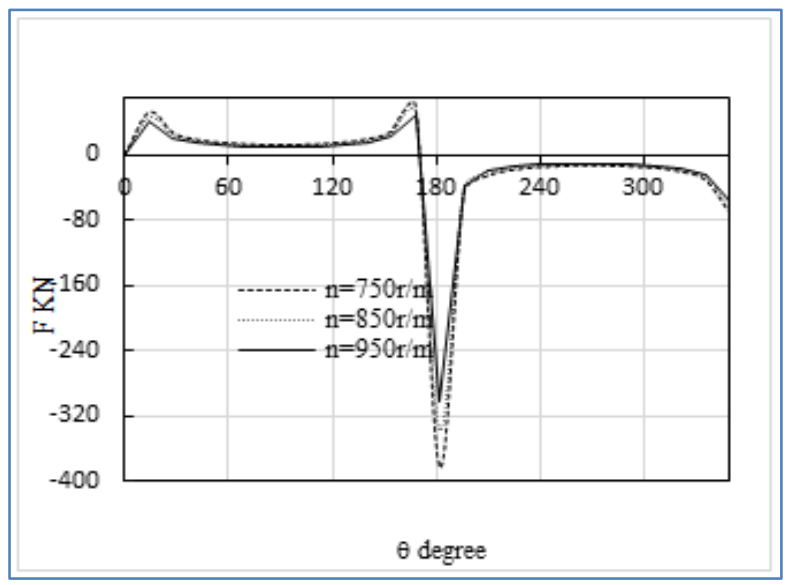

(b) $\mathrm{R}=85 \mathrm{~mm}$

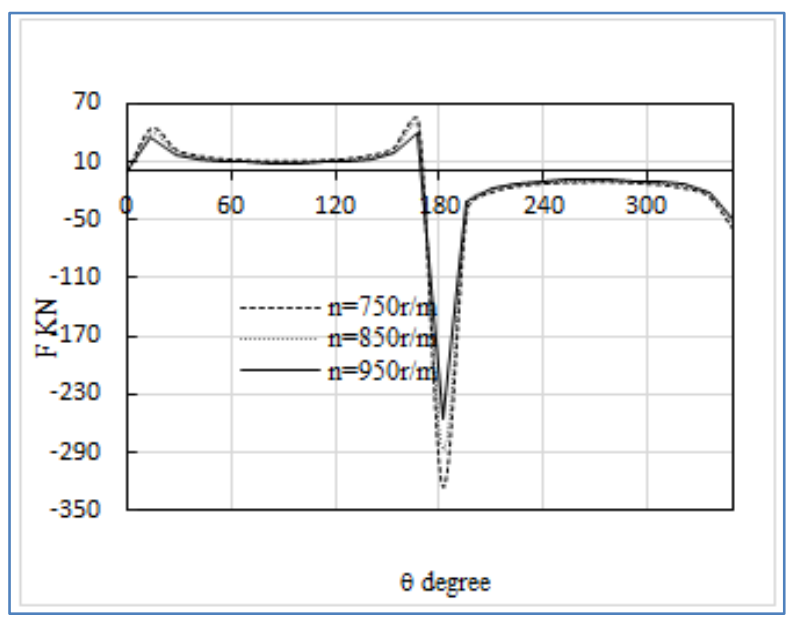

(c) $\mathrm{R}=100 \mathrm{~mm}$

Fig-5: Relations of piston force and angle $\theta_{1}$ with the parameter $R$ and rotation at $85 \mathrm{KW}$ of vehicle

In general the speed and force becomes a periodic wave too with the angle $\theta_{1}$. In a entire cycle $360^{\circ}$ they exhibit the periodic curve. The largest one is when $\mathrm{L}=180 \mathrm{~mm}$ at $180^{\circ}$ that expresses the big force of 
piston for vehicle engine. This is the summit with biggest distance by piston at position $\mathrm{L}+\mathrm{R}$. And then the second summit at $0 \& 360^{\circ}$ at position L-R. The whole distance is $2 \mathrm{R}$ for piston. Here it is considered that the initial place is $\mathrm{L}-\mathrm{R}$ for convenient observation. The effect of crank length and rotation is the similar to about $0 \mathrm{~m} / \mathrm{s}$ and $70 \mathrm{KN}$ respectively in this study. At the force with $750 \mathrm{r} / \mathrm{m}$ and crank length with $100 \mathrm{~mm} \& 70 \mathrm{KW}$ the force will be the lowest which is benefit for engine wear. So the low rpm, long crank length and big power are three parameters affecting the force in engine and crank \& crank craft which should cause engineers and professors in related field to pay many attentions. From the view of the design ones and wear professors these conditions will be alerted to wear engine a certain. On the other hand the stable force status will let the engine decline wear so it is chosen that the destined parameters has declined the unstable one in one cycle of engine in order to avoid the sharper force to form at about $\pi$ radian. The more sluggish will decline the big sharper to be benefit to engine wear.

\section{CONCLUSIONS}

The speed of vehicle becomes periodic wave when the crank angle changes. With the increase of angle the vehicle speed becomes periodic. When the crank length is big the speed shows big one. The similar status will happen in force and the small force summit forms at $0^{\circ}$ and subsequent $360^{\circ}$ in one cycle. At $750 \mathrm{r} / \mathrm{m}$ and $\mathrm{R}=70 \mathrm{~mm}$ the highest force will be formed.
When the rotation is big the force declines from $750 \mathrm{r} / \mathrm{m}$ to $950 \mathrm{r} / \mathrm{m}$. So as angle goes up the force changes in periodic wave and it goes to maximum and minimum in one cycle. So to incline the force it is chosen of short crank length and idling which is the declining cost methods. Moreover the more sluggish will decline the sharper to be benefit to engine wear at $\pi$ radian.

\section{REFERENCES}

1. Wu. W. Kinematics analysis of crank crank length mechanism of internal combustion engine for vehicle, Internal Combustion Engine and Accessories. 019, 5:72

2. Run, X. U. (2020). Modeling of Economic Cost and Technological Control in Motor Housing Punch. Social Science Learning Education Journal, 5(09), 315-324.

3. Run, X. U. (2020). The Simulation of Dynamics and Consumed Fuel on Rotary Inertia of Vehicle. International Journal of Plant Engineering and Management, 25(2), 1-12.

4. Shenghua, L., Longbao, Z. The Internal Combustion Engine to Learn, China Machine Press, 017:115-116

5. Xu, R. (2020). The Kinematic Models of Crank with Angle and Time in Motor Housing Process.

6. Li, Chao-bo., Lou Jing-jun. Dynamic analysis of crank railing mechanism of xingxing air compressor. Chinese Ship Research. 008,5(13), 98 